\title{
OUTCOME OF HONEY DRESSING ON PAIN RELIEF AND RE-EPITHELIZATION OF DONOR SITE WOUND OF SPLIT THICKNESS SKIN GRAFT.
}

1. MBBS, FCPS (Plastic Surgery)

Assistant Professor Plastic Surgery

D.G. Khan Medical College,

D.G. Khan.

2. MBBS, FCPS

Assistant Professor Plastic Surgery

Jinnah Burn and Reconstructive

Surgery Centre Lahore.

3. MBBS

Medical Officer

Jinnah Burn and Reconstructive

Surgery Centre Lahore.

4. MBBS, MS (Anaesthesia)

Assistant Professor Anaesthesia

Jinnah Burn and Reconstructive Surgery Centre Lahore.

5. MBBS, FCPS (General Surgery) Consultant General Surgeon Doctors Hospital Dera Ghazi Khan

6. MBBS, FRCS, FCPS

Professor Plastic Surgery

Jinnah Burn and Reconstructive

Surgery Centre,

Allama Iqbal Medical College

Lahore.

Correspondence Address:

Dr. Abdul Malik Mujahid

Room No. 22, Doctors Hostel,

Teaching Hospital, Dera Ghazi Khan

iqbalian_127@yahoo.com

Article received on:

17/02/2020

Accepted for publication:

02/04/2020

\section{INTRODUCTION}

Skin grafting is one of the most commonly done surgical procedure for skin and soft tissue defects (wounds). It's an important tool in the reconstructive ladder and widely used by reconstructive surgeons. Split thickness skin grafts (STSG) are used in most soft tissue defects after trauma, tumour surgery and burns. STSG represent the rapid and effective method of resurfacing the granulating tissue beds with large skin defects or tissue loss. In large wounds, its application is necessary to prevent contraction. It provides supple skin cover to wounds and prevent healing by secondary intention. As in secondary healing, the scar remains unstable or may convert into hypertrophic scar or keloid. ${ }^{1-3}$ As a principal, the donor site of any reconstructive procedure should heal uneventfully. Similarly, in case of the STSG donor site, the aim is to provide an environment that promotes healing and prevent any complication like infection, pain and delayed healing.

Pain at the skin graft donor site can be a real problem for most patients, especially in the first five to seven postoperative days. Alleviation of this pain can achieve considerable reduction in postoperative morbidity and the fast recovery of the donor site. ${ }^{4}$ These methods include ice application at the donor site, the Fascia Iliaca compartment block, and a number of dressings. ${ }^{5}$ A wound dressing with the goal of moisture preservation, necessary for epithelisation, is generally applied on the donor site. $^{3}$

Conventionally normal saline, hydrogel and hydrocolloid dressings are in use now a days. ${ }^{6}$ However; no optimal dressing has been commonly 
approved. There is a need for new effective agents in topical wound care, and honey shows potential in this regard. Honey comes from natural source and is of high nutritional value. It is Antioxidant and bacteriostatic and has antimicrobial and antiinflammatory characteristics as well. It provides moist environment when used topically on wound site $^{7}$, having the properties of clearing existing infection, debride wound. It reduces edema, prevents or minimizes hypertrophic scarring and hasten healing. ${ }^{8}$ Honey stimulates inflammatory response in leucocytes ${ }^{9}$, triggers the cascade reaction which produces growth factors which are responsible for angiogenesis and the proliferation of fibroblast and epithelial cells. It permits epidermal migration and provide trace nutrients that accelerate healing and re-epithelization. ${ }^{10}$

In a study by Subrahmanyam M in 2012 reported that $90 \%$ of the patients had nil or only moderate pain without any allergic reaction in patients managed with honey. On the $7^{\text {th }}$ post-operative follow-up day, epithelialization was occurred in $48(96 \%)$ patients. By the $10^{\text {th }}$ day, all $(100 \%)$ the wounds were healed/epithelized. ${ }^{11}$

The rationale of this study is to determine the frequency of pain relief and re-epithelization of the donor site wound of split thickness skin graft with the use of honey dressing. No local study is available in literature, so the results would result in change of clinic practice and will add in evidencebased practice.

\section{MATERIAL \& METHODS}

This study was conducted at the Plastic Surgery Department, from $1^{\text {st }}$ January 2019 to $30^{\text {th }}$ November 2019. The sample size of 100 cases is calculated with 95\% confidence level, 5\% margin of error and taking expected percentage of pain relief i.e. $90 \%$ of honey dressing on the donor site wound of split thickness graft. Patients full filling the inclusion criteria (either gender, age between 18 to 60 years and wound with healthy granulation tissue for skin grafting) were selected through non-probability consecutive sampling. Patients with known malignancy (were assessed on their medical record), radiation, Diabetes mellitus, hypertension and bleeding disorder were excluded from study. After the approval from the ethical committee of the hospital, informed consent was obtained from all the patients. After the baseline investigations and assessment of the patient for fitness, pre-operative photography was done for the record. All patients underwent operations under general anaesthesia by the same surgeon. After harvesting of split thickness skin graft, donor site was dressed by a layer of honey on gauze piece $(5 \mathrm{gm} / 20 \mathrm{~cm})$ wrap around the donor wound site. Dressing was done once and patients were followed at the $7^{\text {th }}$ day post operatively and the outcome measures i.e. pain relief \& re-epithelization were noted on specially designed Performa. Data was entered and analysed using SPSS 22. For the quantitative variables like the age, the size of wound and pain (Visual Analogue Scale) mean and standard deviation was calculated. Qualitative variables like gender, pain relief and re-epithelization was calculated in the form of frequencies and percentages. Data was stratified for age, gender and the size of the wound. The post stratified chi-square test was applied to see role of effect modifiers. $p$-value $\leq 0.05$ was considered as significant.

\section{RESULTS}

During the study period 100 cases were enrolled. The mean age of patients was 33.11 \pm 9.72 years. (Table-I) Gender distribution of patients showed that there were $45 \%$ females and $55 \%$ male patients included in the study. (Figure-1). Mean wound size was $7.70 \pm 1.83 \mathrm{~cm}$. Minimum and maximum wound size was 5.10 and $11.80 \mathrm{~cm}$ respectively. (Table-II). At the $7^{\text {th }}$ post-operative day, $74(74 \%)$ patients had pain relief (the VAS score of 3 or less) (Table-III) and $78(78 \%)$ patients had achieved re-epithelialization (Table-III). The pain relief at the $7^{\text {th }}$ day was not significantly associated with the age group of patients. i.e. 18-30 years: $71.4 \%, 31-50$ years: $76.6 \% \&>50$ years: $75 \%$ ( $p$-value $=0.846)$ (Table-IV).

\begin{tabular}{|l|c|}
\hline \multicolumn{1}{|c|}{$\mathbf{N}$} & $\mathbf{1 0 0}$ \\
\hline Mean & 33.11 \\
\hline SD & 9.72 \\
\hline Minimum & 18 \\
\hline Maximum & 60 \\
\hline \multicolumn{2}{|c|}{ Table-I. Age distribution of patients } \\
\hline
\end{tabular}

Table-I. Age distribution of patients 


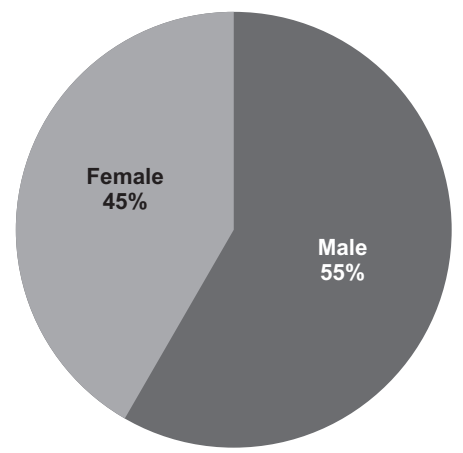

Figure-1. Gender distribution of patients

\begin{tabular}{|l|c|c|}
\hline \multicolumn{1}{|l|}{$\mathbf{N}=100$} \\
\hline Mean
\end{tabular}

\section{DISCUSSION}

Most of skin and soft tissue defects need some form of reconstruction depending on the size and location of defects. Split thickness skin grafting (STSG) is an important reconstruction tool in trauma and major burns. The simplicity of the procedure has made it a popular reconstructive option in developing and many developed countries. The donor site wound should heal completely within 7 to 21 days in ideal conditions depending on the thickness of graft. Optimum local wound care at both the recipient and the donor site should promote wound healing and be cost-effective, while preventing adverse effects or complications, such as discomfort, infection, pain, and scarring. ${ }^{12}$ The donor site dressing is considered as an ideal which should be easy to apply, promote rapid re-epithelialization and relatively inexpensive. ${ }^{13}$ Dressings that are more comfortable and have shorter healing time with improved skin quality after healing, would grant patients a better quality of life.

Although STSG is the standard of care for full thickness burn wounds, complications, such as impaired healing, infection, excessive pain, scarring, pruritus, and either hypopigmentation or hyperpigmentation, are common on the donor site. Among these, the pain at the donor site is most reported and distressing symptoms reported by patients in the early postoperative period..$^{14}$ Larger donor sites stimulate a greater number of pain receptors and consequently pain is proportional to the size of the graft harvested. Often, the donor site is reported to be more painful than the recipient site, affecting early mobilization, sleep, and need for analgesics postoperatively. The donor site pain is also a significant stressor during hospitalization and the uncontrolled pain in the acute setting is a predictor of developing chronic pain in burn patients. ${ }^{15-18}$ Postoperative care for pain management after skin graft procedures usually requires multimodal therapy. Clinically significant physiology changes occur in burn patients which complicate pain management. The response to standard drugs is also altered in these patients. ${ }^{19}$

The characteristics of ideal donor site dressing would be ease of application, no pain, prevent infection and reduce cost. ${ }^{20}$ For an ideal donor site dressing the following considerations are important which includes ease of application, less painful, low infection rate, early re-epithelialization and cost effective. ${ }^{21}$ The traditional dressing used for the donor site is non adherent Vaseline impregnated gauze with the aim to prevent trauma and infection. The other dressings reported in literature can be divided in to moist dressings like Xeroform, Jelonet and non-moist dressings like Kaltostat, Aquacel Ag, Tegaderm. ${ }^{21}$ 
Use of honey in wound management is evident since ancient time. The evidence is present in existing literature of different cultures including Ayurvedic, Chines, Greek and Roman cultures. Honey (mixture of sugars) is produced by the bees from natural source i.e. flowers nectar. The medical grade Manuka honey has antibacterial activity due to the presence of peroxides. It inhibits over 50 different bacteria, but does not show any microbial resistance. It also promotes autolytic debridement in wounds. ${ }^{22-24}$ Honey impregnated gauze is a semi occlusive dressing and it promotes wound healing, reduces the pain of dressing changes and prevents infections in burn wounds. ${ }^{23,25,26}$

Use of honey in animals' models showed early wound healing as compared to the traditional dressings. The Use of non-medical honey is condemned, as it may contain microbes and spores which can contaminate the wounds. ${ }^{22-24}$

There is one study by M. Subrahmanyam, who evaluated the effect of honey on skin graft donor sites. The study showed excellent pain relief (90\%) with honey dressing. The re-epithelization was seen in 48 (96\%) patients of honey dressing as compared to 39 (78\%) patients in Vaseline gauze group on $7^{\text {th }}$ day $(p<0.05)$. The healing was seen in $100 \%$ of the cases in honey dressing group on day $10^{\text {th }}(p<0.05)$. Patient satisfaction was comparable in both groups at one-month follow-up. ${ }^{27}$

In the present study, it was observed that the outcome of honey dressing on donor site wound of the split thickness skin graft in terms of pain relief and re-epithelization is good. At the $7^{\text {th }}$ postoperative day the pain control was seen in $74 \%$ while re-epithelization was seen in $78 \%$ of the cases. This result showed that both the outcome measures i.e. pain relief and re-epithelialization was better with the use of honey dressing. The existing literature on this concept is limited both nationally and internationally.

Age, gender and wound size was stratified to see if these variables affect the outcome of honey dressing on pain relief and re-epithelization. No statistically significant difference was seen for pain relief and re-epithelization in terms of age, gender and wound size of patients. Pain relief at the $7^{\text {th }}$ Day: $18-30$ Years, $71.4 \%, 31-50$ years: $75 \%$ and $>50$ years: $75 \%$. Re-epithelization at the $7^{\text {th }}$ Day: $18-30$ Years, $81.6 \%, 31-50$ years: $76.6 \%$ and $>50$ years: $50 \%$. Pain relief at the $7^{\text {th }}$ Day: Male: $74.5 \%$ vs. Female: $73.3 \%$. Re-epithelization at the $7^{\text {th }}$ Day: Male: $81.8 \%$ vs. Female: $73.3 \%$ respectively. Pain relief at the $7^{\text {th }}$ Day in patients with wound size was: $5-7,75 \%, 8-10: 78.6 \%$ and $>10: 64.3 \%$. Re-epithelization at the $7^{\text {th }}$ Day in patients with wound size: $5-7,81.9 \%, 8-10: 71.4 \%$ and $>10: 64.3 \%$ respectively.

The results of this study are almost comparable and supported by the findings reported by $\mathrm{M}$. Subrahmanyam, who in his study concluded that the use of honey-impregnated gauze is safe when used at donor site. It promotes healing, with excellent donor site healing.

\section{CONCLUSION}

Based on the findings of this study it can be said that honey dressing is useful and effective on the donor site wound of split thickness skin graft in terms of pain relief and re-epithelization.

\section{Acknowledgement}

I am thankful to Professor Moazzam Nazeer Tarar and Dr Husnain Khan for their guidance throughout the study

\section{Conflict of Interest}

Authors have no financial or personal interests with any people or organisation that would influence this work

Copyright $@ 02$ Apr, 2020.

\section{REFERENCES}

1. Aerden D, Bosmans I, Vanmierlo B, Spinnael J, Keymeule $B$, Van den Brande P. Skin grafting the contaminated wound bed: reassessing the role of the preoperative swab. J Wound Care 2013; 22(2): 85-9.

2. Blume PA, Key JJ, Thakor P, Thakor S, Sumpio B. Retrospective evaluation of clinical outcomes in subjects with split $\square$ thickness skin graft: comparing VAC ${ }^{\circledR}$ therapy and conventional therapy in foot and ankle reconstructive surgeries. Int Wound J. 2010; 7(6): 480-7. 
3. Donegan RJ, Schmidt BM, Blume PA. An overview of factors maximizing successful split-thickness skin grafting in diabetic wounds. Diabetic Foot Ankle 2014; 5(1): 1-11.

4. Voineskos SH, Ayeni OA, McKnight L, Thoma A. Systematic review of skin graft donor-site dressings. Plast Reconstr Surg 2009; 124(1): 298-306.

5. Uygur F, Evınc R, Ulkur E, Celıkoz B. Use of lyophilized bovine collagen for split-thickness skin graft donor site management. Burns 2008; 34(7): 1011-4.

6. Kaiser D, Hafner J, Mayer D, French LE, Läuchli S. Alginate dressing and polyurethane film versus paraffin gauze in the treatment of split-thickness skin graft donor sites: a randomized controlled pilot study. Adv in skin \& wound care. 2013; 26(2):67-73.

7. Haynes JS, Callaghan R. Properties of honey: Its mode of action and clinical outcomes. Wounds UK. $2011 ; 7(1): 50-7$.

8. Noori A, Al Ghamdi A, Ansari MJ, Al-Attal Y, Al-Mubarak $A$, Salom K. Differences in composition of honey samples and their impact on the antimicrobial activities against drug multiresistant bacteria and pathogenic fungi. Arch Med Res. 2013; 44(4):307-16.

9. Mandal MD, Mandal S. Honey: Its medicinal property and antibacterial activity. Asia Pac J Trop Biomed. 2011; $1(2): 154-60$.

10. Molan PC. The evidence and the rationale for the use of honey as wound dressing. Wound Prac Res. 2011; 19:204-20.

11. Subrahmanyam M. Honey dressing accelerates splitthickness skin graft donor site healing. Indian J Surg. 2012:1-3: DOI 10.1007/s12262-012-0789-9.

12. Lars PKLP,Giretzlehner M, Trop M, Parvizi D, Spendel S, Schintler $\mathrm{M}$ et al. The properties of the "ideal" donor site dressing: results of a worldwide online survey. Ann Burns Fire Disasters 2013; 26(3): 136-41.

13. Olawoye OA, Ademola SA, Iyun AO, Michael Al, Oluwatosin OM. Management of split skin graft donor site in the West African sub region: Survey of plastic surgeons' practice. Ann Burns Fire Disasters 2017; 30(2): 146-9.

14. Sinha S, Schreiner AJ, Biernaskie J, Nickerson D, Gabriel VA. Treating pain on skin graft donor sites: Review and clinical recommendations. J Trauma Acute Care Surg 2017; 83: 954-64.
15. Lowrie AG, Dabernig J, Watson SB. Operative techniques for the minimization of skin graft donorsite pain in flap surgery. Plast Reconstr Surg. 2007; 119(4): 1393-4.

16. Feldman DL, Rogers A, Karpinski RH. A prospective trial comparing Biobrane, Duoderm and xeroform for skin graft donor sites. Surg Gynecol Obstet. 1991; 173(1): 1-5.

17. Burnett LN, Carr E, Tapp D, Raffin Bouchal S, Horch JD, Biernaskie J, et al. Patient experiences living with split thickness skin grafts. Burns. 2014; 40(6): 1097-105.

18. Wiechula $R$. The use of moist wound-healing dressings in the management of split-thickness skin graft donor sites: A systematic review. Int J Nurs Pract. 2003; 9(2): S9-S17.

19. Dissanaike S, McCauley J, Alphonso C. Liposomal bupivacaine for the management of postsurgical donor site pain in patients with burn injuries: $A$ case series from two institutions. Clin Case Rep 2018; 6(1): 129-35.

20. Winter GD. A note on wound healing under dressings with special reference to perforated-film dressings. J Invest Dermatol. 1965; 45(4): 299-302.

21. Salisbury RE, Wilmore DW, Silverstein P, Pruitt BA. Biological dressings for skin graft donor sites. Arch Surg. 1973; 106(5): 705-6.

22. Lipsky BA, Hoey C. Topical antimicrobial therapy for treating chronic wounds. Clin Infect Dis 2009; 49(10): 1541-9.

23. Jull $A B$, Rodgers $A$, Walker N. Honey as a topical treatment for wounds. Cochrane Database Syst Rev. 2008; 4

24. Jull AB, Walker N, Deshpande S. Honey as a topical treatment for wounds. Cochrane Database Syst Rev. 2013; 2(2).

25. Baghel P, Shukla S, Mathur R, Randa R. A comparative study to evaluate the effect of honey dressing and silver sulfadiazene dressing on wound healing in burn patients. Indian J Plast Surg. 2009; 42(2): 176.

26. Bangroo A, Khatri R, Chauhan S. Honey dressing in pediatric burns. J Indian Assoc Pediatr Surg. 2005; 10(3): 172.

27. Subrahmanyam M. Honey Dressing Accelerates Split-Thickness Skin Graft Donor Site Healing. Indian J Surg. 2015; 77(2): 261-3. 


\section{What comes easy won't last. What lasts won't come easy.}

\section{"Unknown"}

\begin{tabular}{|c|c|c|c|}
\hline \multicolumn{2}{|c}{ AUTHORSHIP AND CONTRIBUTION DECLARATION } \\
\hline Sr. \# & Author(s) Full Name & \multicolumn{1}{|c|}{ Contribution to the paper } & Author(s) Signature \\
\hline 1 & Abdul Malik Mujahid & $\begin{array}{l}\text { Principal contributor, } \\
\text { Conceptualization and design of } \\
\text { research work, data collection. } \\
\text { Data collection, statistical } \\
\text { analysis, interpretation of data. } \\
\text { Writing of manuscript, resutls } \\
\text { analysis. } \\
\text { Drafting literature search, data } \\
\text { collection, final review. }\end{array}$ \\
\hline 5 & Farrukh Aslam Khalid & Kashif Khan Niazi & $\begin{array}{l}\text { Literature search, statistical } \\
\text { analysis, revision of manuscript. } \\
\text { Drafting, review of results and } \\
\text { final approval. }\end{array}$ \\
\hline
\end{tabular}

